RESEARCH ARTICLE

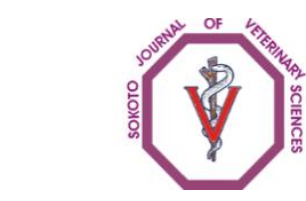

Sokoto Journal of Veterinary Sciences

(P-ISSN 1595-093X/ E-ISSN 2315-6201)

Mshelia et al/Sokoto Journal of Veterinary Sciences (2014) 12(1): 18-22.

http://dx.doi.org/10.4314/sokjvs.v12i1.3

\title{
Microbiological studies on genital infections in slaughtered ewes from tropical arid zone of Nigeria
}

\author{
GD Mshelia ${ }^{1}$, VT Bilal ${ }^{1}$, VA Maina ${ }^{1}$, K Okon $^{2}$, SA Mamza ${ }^{1}$, ID Peter ${ }^{1} \&$ GO Egwu $^{1}$ \\ 1. Faculty of Veterinary Medicine, University of Maiduguri, Borno State-Nigeria \\ 2. Federal Medical Centre, Makurdi-Nigeria
}

\begin{abstract}
*Correspondence: Tel.: 2347039868025, E-mail: gdmshelia@yahoo.co.uk
Abstract

An abattoir survey was undertaken to investigate genital bacterial infections of ewes in tropical arid zone of Nigeria. Vaginal and uterine samples were collected and cultured using standard bacteriological techniques. The results of the study showed that the isolates were Escherichia coli (32\%), Staphylococcus spp (26\%), Klebsiella spp (16\%), Pseudomonas (15\%) and Proteus (11\%); wherein E coli and $S$ aureus were the most common bacterial isolates. The bacterial population in the vagina $(64 \%)$ was significantly $(p<0.05)$ higher than that in the uterus (34\%). The antibiotic susceptibility test revealed that E. coli was highly susceptible (100\%) to Amoxycillin, Ampicillin, Amoxycillin-clavulanate and Pefloxacin, whereas low susceptibility was observed against Ciprofloxacin and Ofloxacin (10 and $22 \%$ respectively). S. aureus showed $100 \%$ susceptibility to Amoxycillin-clavulanate, Gentamicin, Nalidixic acid and Pefloxacin, whereas susceptibility against Streptomycin, Amoxycillin, Ciprofloxacin and Ofloxacin was in declining order $(46,33,30$ and $20 \%$ respectively). The potentials of these microbes for producing pathogenicity in genital tract of ewes is likely to be high in Nigeria. Therapeutic use of these antimicrobial agents will help to reduce infectious reproductive diseases in ewes, though in-vivo trials are further required for establishing their efficacy in controlling genital infections in ruminants.
\end{abstract}

Keywords: Antimicrobial susceptibility, Ewes, E. coli, S. aureus, Genital infections

Received: 10-08-2013

Accepted: 15-01-2014

\section{Introduction}

Genital infections in domestic ruminants are often caused by opportunistic secondary invaders, especially Escherichia coli species, that have frequently been isolated in majority from ewes (Manes et al., 2010; Martins et al., 2009; Sargison et al., 2007), goats (Ababneh \& Degefa, 2006) and cows (Sheldon et al., 2008). Coliforms (of fecal origin) and other non-specific bacteria are also opportunistic pathogens in the reproductive tract. Under stressful conditions, these opportunist bacteria may cause genital infection that usually leads to reproductive failure in ruminants (Levinson \& Jawetz, 1994; Shallali et al., 2001).

The antimicrobial susceptibilities of these isolates in tropical arid zones may vary; thus, limiting the efficacy of the common treatment protocols in use in these areas. Unlike in cattle, information regarding the use of antibiotics in the control of reproductive diseases in ewes is inadequate (Martins et al., 2009). An understanding of the bacterial species colonizing the ovine vagina and uterus; and their antimicrobial susceptibility patterns will therefore clarify the practical management of these genital infections in ewes. This study was therefore designed to investigate the prevalence of genital bacterial infections and their antimicrobial susceptibility patterns in ewes reared in the tropical arid zone of Nigeria.

\section{Materials and methods}

Geo-climatic conditions of the Study area

The study was conducted in Maiduguri, an arid zone of Nigeria situated at an altitude of $354 \mathrm{~m}$, between latitudes $10.2^{\circ} \mathrm{N}$ and $13.4^{\circ} \mathrm{N}$ and longitudes $9.8^{\circ} \mathrm{E}$ and $14.4^{\circ} \mathrm{E}$. The climate of the area for most of the year is hot and dry; the wet season generally starts from 
June to September or early October. Temperature range from $13-41^{\circ} \mathrm{C}$, annual rainfall 9-198mm, sunshine of 7-9 hours/day and relative humidity of $19-78 \%$, which remains around $45 \%$ during the wet season.

\section{Sample Collection from the Animals}

A total of 100 genitalia were collected from Balami, Uda and Yankasa ewes immediately after slaughter at the Maiduguri abattoir. These were immediately transported to the diagnostic laboratory in sterile polythene bags. The vaginal and uterine samples were collected as per standard protocols described by Amin et al. (1996) and Cheesbrough (1985). Accordingly, the surface of the uterus was sterilized by shearing the uterine wall with preheated surgical blade thereafter uterine wall was lanced with another sterile blade and a sterile swab stick

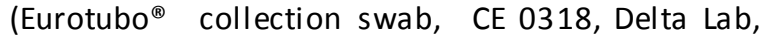
08191 Rubi, Spain) was inserted and rolled over into the uterine lumen to collect bacteriological samples.

\section{Culture, isolation and identification of bacteria}

The swab samples collected were inoculated on to conventional culture media for the isolation and purification of bacteria. These media include Blood agar (BA), MacConkey agar (MA), Nutrient agar (NA) and $10 \%$ Mannitol salt agar (MSA) (Oxoid, Basingstoke, UK). Inoculated media were incubated both aerobically and anaerobically at $37^{\circ} \mathrm{C}$ for 24 hours to cultivate bacteria. The colonies grown on these culture media were further repeatedly subcultured for 2-7 days on to NA, BA and other differential culture media MA, Eosin methylene blue (EMB) agar and Chocolate agar (CA) according to standard protocols (Cheesbrough, 1985). The growths observed were isolated, purified and identified according to Cowan \& Steel (1993).

\section{Antibiotic susceptibility tests}

The susceptibility pattern of E. coli and S. aureus were studied against a panel of el even antimicrobial agents namely: Amoxycillin, Ampicillin, Amoxycillinclavulanate, Ceporexin, Ciprofloxacin, Gentamicin, Nalidixic acid, Norfloxacin, Pefloxacin, Streptomycin and Ofloxacin. These antibiotic drugs were tested according to a modification of the protocol described by Biruhtesfa et al. (2007). Briefly, distinct colonies of pure isolates grown on Blood and MacConkey agar plates were selected and transferred to tubes containing $5 \mathrm{~mL}$ of Brain Heart Infusion broth. The inoculated cultures were then standardized to a turbidity equivalent to a 0.5 McFarland standard corresponding to a concentration of approximately $1-2 \times 10^{8} \mathrm{CFU} / \mathrm{mL}$. Ten (10) $\mu \mathrm{L}$ of the bacterial suspension was dispensed and spread onto the nutrient agar before placement of the antibiotic discs (Optudisc, Optum Laboratory, Lagos, Nigeria). These were then incubated for 24 hours at $37^{\circ} \mathrm{C}$ before the inhibition zones were measured.

Data Analysis

The distribution of the bacterial isolates was estimated as simple percentages and data subjected to test of significance using the Chi-square test. The susceptibility patterns of $E$. coli and $S$. aureus against the panel of antimicrobial agents tested were analysed with Microsoft Excel. P-value was considered significant at 0.05

\section{Results}

From a total of 100 samples collected, 138 isolates were recovered from the ovine uterus and vagina. Of this number, five genera of aerobic bacteria were identified which include Escherichia coli (31.9\%), Staphylococcus spp (26.1\%), Klebsiella spp (15.9\%), Pseudomonas (15.2\%) and Proteus (10.9\%). The isolation rate of vaginal bacteria $91 / 138$ (66\%) was almost double the rate for the uterine isolates 47/138 (34\%) (Table1).

The antimicrobial susceptibility patterns of genital $S$. aureus and E. coli isolated in the present study are shown in Figure 1 . The result showed that E. coli was highly susceptible (100\%) to Amoxycillin, Ampicillin, Amoxycillin-clavulanate, Norfloxacin and Pefloxacin, whereas the susceptibility was observed to be low against Ciprofloxacin and Ofloxacin (10 and 22\% respectively). Amoxycillin-clavulanate, Gentamicin, Nalidixic acid and Pefloxacin were $100 \%$ effective against $S$. aureus, whereas the effectiveness of Streptomycin, Amoxycillin, Ciprofloxacin and Ofloxacin against $S$. aureus was in declining order $(46,33,30$ and $20 \%$ respectively). 
Table 1: Comparison of vaginal and uterine bacteria isolates

\begin{tabular}{llll}
\hline Micro organisms isolated & \multicolumn{3}{c}{ Number of isolates (\%) } \\
\hline \multirow{3}{*}{ Staphylococcus aureus } & $20(22.0)$ & $16(34.0)$ & $36(26.1)$ \\
\cline { 2 - 4 } Proteus spp & $10(10.9)$ & $5(10.6)$ & $15(10.9)$ \\
Escherichia coli & $34(37.4)$ & $10(21.3)$ & $44(31.9)$ \\
Klebsiella spp & $14(15.4)$ & $8(17.3)$ & $22(15.9)$ \\
Pseudomonas spp & $13(14.3)$ & $8(17.3)$ & $21(15.2)$ \\
Total & $91(100)$ & $47(100)$ & $138(100)$ \\
\hline
\end{tabular}

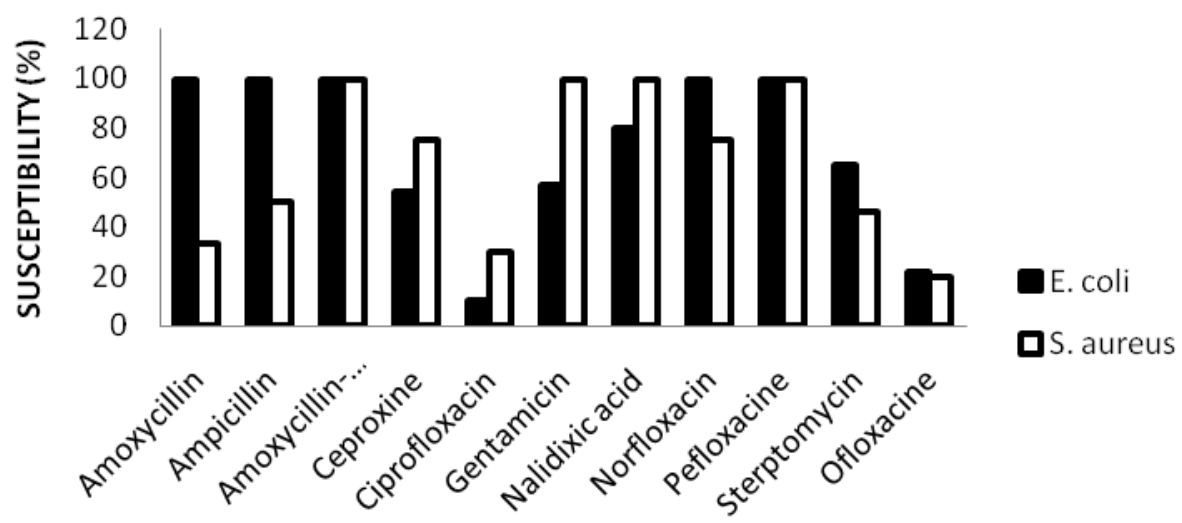

ANTIMICROBIAL AGENTS

Figure1: Antimicrobial susceptibility patterns of genital E. coli and S. aureus isolates from Nigerian ewes

\section{Discussion}

Bacteria colonizing the vagina and uterus are likely to cause reproductive failure in ewes and other domestic ruminants. Vaginal bacteria get access into the uterus during the peripartum period leading to metritis and endometritis and subsequent reduction in the reproductive capacities of these animals (Levinson \& Jawetz, 1994). It is therefore important to identify these bacteria with the view of providing remedial interventions that will restore fertility.

In the present study, Escherichia coli, Staphylococcus aureus and Klebsiella spp were the most common genital bacterial isolates observed in ewes in the arid zone of Nigeria. This finding is similar to the observation made by Sokkar et al. (1980) who found E coli, Corynebacterium pyogenes and Staphylococcus aureus as the most common uterine flora in some ewes, associated with endometritis. In a recent study in cows, Gani et al. (2008) reported Staphylococus (37.8\%), Bacillus (35.1\%), Escherichia coli (29.7\%) and Pseudomonas (18.9\%) as the major genital isolates from repeat breeders with mucopurulent vaginal discharges. The presence of $E$. coli with other isolates such as Corynebacterium pyogenes, Streptococcus, Bacillus and Staphylococcus aureus from cases of endometritis (Adams, 1975; Gamcik et al. 1975); and with Klebsiella pneumonia and Staphyloccus aureus from cases of vaginitis have been reported in ewes (Martins et al., 2009). The importance of E. coli as a cause of genital disorders in animals cannot be ignored, because it has been isolated most frequently in association with pyometra in ewes (Adams, 1975) and bitches (Sandholm et al., 1976). In the present study, the isolates were more commonly found in the vagina (66\%) than the uterus (34\%) which is in contrast with the report of one study in Sudanese sheep and goats (Shallali et al., 2001). The significance of these isolates as causes of lowered reproductive efficiency in ewes could not be ascertained from the present study. A correlation of clinical parameters with reproductive history of live animals would have elucidated on the importance of the isolates. This is certainly a major limitation of the present study. Where possible, gynaecological 
evaluations in live animals should proceed with proper history, clinical and laboratory examination in order to determine specific aetiologies and generate useful data for effective diagnosis of genital disorders. This approach coupled with assessment of serum hormone profiles could hasten decisions for or against remedial measures to be deployed in the management of reproductive disturbances (Ferreira et al., 2008). For example, it has been suggested that under oestrogenic influence (follicular phase), the uterus is more resistant to bacterial invasion than during the prevalence of high progesterone (luteal phase) in animals (Adams, 1975; Amin et al., 1996). This phenomenon has recently been demonstrated with vaginal bacterial isolates in ewes treated with intravaginal progesterone device (Manes et al., 2010). Therefore, the determination of the hormonal status of the animal is essential in interpreting the significance of genital bacterial isolates.

The rate of isolation of $S$. aureus was significantly higher $(p<0.05)$ in the uterus compared to the vagina; and conversely so for $E$ coli from the vagina than the uterus. But the overall weight of infection in the vagina was almost twice the rate in the uterus. This is likely due to the continuous contamination of the vagina by faeces that could lead to bacterial colonization of the vaginal environment (Levinson \& Jawetz, 1994).

From the result of the present study, it was observed that the susceptibility of the $E$ coli isolates were high (100\%) against Amoxycillin, Ampicillin, Amoxycillinclavulanate, Norfloxacin and Pefloxacin; but with other antimicrobial agents such as Ciprofloxacin and Ofloxacin, their susceptibility was low ranging from 10 to $22 \%$ respectively. From the observations made in the present study, the susceptibility pattern of the $E$ coli isolates is similar to what was reported by Emikpe et al. (2009) in goats in southern Nigeria, but in variance with previous observations made

\section{References}

Ababneh MM \& Degefa T (2006). Bacteriological findings and hormonal profiles in the postpartum Balady goats. Reproduction in Domestic Animals, 41(1): 12 - 16.

Adams NR (1975). A pathological and bacteriological abattoir survey of the reproductive tracts of merino ewes in Western Australia. Australian Veterinary Journal, 51(7): 351354.

Amin JD, Zaria LT \& Malgwi RM (1996). Vaginal aerobic bacterial flora of apparently healthy elsewhere (Goncuoglu et al., 2010; Khan et al., 2004; Martins et al., 2009). For example, while both Goncuoglu et al., (2010) and Martins et al., (2009), showed that Ciprofloxacin was highly effective (100\%) against vaginal $E$ coli isolates, our study demonstrated low susceptibility (10\%) of this pathogen to Ciprofloxacin. The observation in the present study presents concern with the use of this agent in the treatment of $E$ coli associated genital infections in ewes in this part of the world. Further studies will be required to make clear this divergent finding in this area.

For the $S$ aureus isolates, the susceptibility pattern was highest (100\%) against Amoxycillin-clavulanate, Gentamycin, Nalidixic acid and Pefloxacin; with a lower range of 20 to $46 \%$ against Ofloxacin, Ceprofloxacin, Amoxycillin and Streptomycin. There is an increasing antimicrobial resistance in staphylococcal infection in animals, which is complicating empirical selection of antimicrobial agents in veterinary practice. These complications are continuously evolving, in relation to factors such as the site of isolation, sex, age and species of the animal (Hoesktra \& Paulton, 2002).

In conclusion, this study revealed that Escherichia coli , Staphylococcus spp, Klebsiella spp, Pseudomonas and Proteus were the most common vaginal and uterine bacterial isolates in ewes in Nigeria; with $66 \%$ of these recovered from the vagina. These organisms are susceptible to most of the antimicrobials tested. The potentials of these genital bacterial isolates for producing reproductive diseases in ewes is likely to be high in this area; but the treatment of reproductive disorders associated with these pathogens will present some concern to the veterinarian and farmers regarding variation in their susceptibility to the antimicrobial agents in common use in Nigeria. This situation will certainly require further studies in ruminant livestock reared in the tropical arid zone of Nigeria.

cattle in various stages of the reproductive cycle in the Sahel region of Nigeria. Bulletin of Animal Health and Production in Africa, 44(1): 15-18.

Biruhtesfa A, Yilikal A, Bojia E, Ayele G \& Getachew $M$ (2007). Aerobic bacterial isolates in equids and their antimicrobial susceptibility pattern. International Journal of Applied Research in Veterinary Medicine, 5(3): 107112. 
Cheesbrough M (1985). Culturing of anaerobes. In: Medical Laboratory Manual for Tropical Countries. Butterworth Co., Kent, UK. Pp 248-264.

Cowan SJ \& Steel KJ (1993). Manual of identification of medical bacteria. Third edition. Cambridge University Press, Cambridge. Pp 22-126.

Emikpe BO, Oyero OG \& Akpavie SO (2009). Isolation and antibiogram of aerobic nasal bacterial flora of apparently healthy West African dwarf goats. Revue d'elevage et de Medecine Veterinaire des Pays Tropicaux, 62(1): 17-21.

Ferreira R, Oliveira JFC, Antoniazzi AQ, Pimentel CA, Moraes JCF, Henkes LE, Bordignon V \& Gonçalves PBD (2008). Relationship between clinical and postmortem evaluation in repeat breeder beef cows. Ciencia Rural (Santa Maria), 38(4): 10561060.

Gamcik P, Nemes D \& Schvare F (1975). Bacteriological findings in the genital organs of sheep in the course of oestrus synchronization, pregnancy and the puerperium. Folia Veterinaria, 19(1-2): 359366.

Gani MO, Amin MM, Alam MGS, Kayesh MEH, Karim MR, Samad MA \& Islam MR (2008). Bacterial flora associated with repeat breeding and uterine infections in dairy cows. Bangladesh Journal of Veterinary Medicine, 6(1): 79-86.

Goncuoglu M, Ormanci FSB, Ayaz ND \& Erol I (2010). Antibiotic resistance of Escherichia coli 0157:H7 isolated from cattle and sheep. Annals of Microbiology, 60(3) 489-494.

Hoesktra KA \& Paulton RJL (2002). Clinical prevalence and antimicrobial susceptibility of Staphylococcus aureus and Staphylococcus intermedius in dogs. Journal of Applied Microbiology, 93(3) 406-413.

Khan AZ, Khan A, Hayat CS, Munir Z \& Ayaz U (2004). Prevalence of Mastitis in buffaloes and antibiotics sensitivity profiles of isolates. Pakistan Journal of Life and Social Sciences, 2(1): 73-75.

Levinson WE \& Jawetz E (1994). Medical Microbiology and Immunology. Third edition. Prentice-Hall Int. Inc., Englewood Cliffs, New Jersey-USA. Pp 20-23.

Manes J, Fiorentino MA, Kaiser G, Hozbor F, Alberio $R$, Sanchez $E$ \& Paolicchi $F$ (2010). Changes in the aerobic vaginal flora after treatment with different intravaginal devices in ewes. Small Ruminant Research, 94(1-3): 201-204.

Martins G, Figueira L, Penna B, Brandão F, Varges $R$, Vasconcelos C \& Lilenbaum W (2009). Prevalence and antimicrobial susceptibility of vaginal bacteria from ewes treated with progestin-impregnated intravaginal sponges. Small Ruminant Research, 81(2-3): 182-184.

Sandholm M, Vasenius H \& Kivisto AK (1976). Pathogenesis of canine pyometra. Journal of American Veterinary Medical Association, 167(11): 1006 -1010.

Sargison ND, Howie F, Mearns R, Penny CD, Foster G (2007). Shiga toxin-producing Escherichia coli as a perennial cause of abortion in a closed flock of Suffolk ewes. Veterinary Record, 160(25): 875-876.

Shallali AA, Hussein AM, Salih MM \& Dafalla EA (2001). A preliminary report on bacteria isolated from the female genital tract of sudanese sheep and goats. The Sudan Journal of Veterinary Research, 17(1): 5563.

Sheldon IM, Williams EJ, Miller AN, Nash DM \& Herath S (2008). Uterine diseases in cattle after parturition. Veterinary Journal, 176(1): $115-121$.

Sokkar SM, Kubba A \& Al-Augaidy F (1980). Studies on natural and experimental endometritis in ewes. Veterinary Pathology, 17(6): 693698. 